\title{
A Combined QM/MM Molecular Dynamics Simulations Study of Nitrate Anion $\left(\mathrm{NO}_{3}{ }^{-}\right)$in Aqueous Solution
}

\author{
Anan Tongraar, ${ }^{* \dagger} \dagger$ Piyawan Tangkawanwanit, ${ }^{\dagger}$ and Bernd Michael Rode ${ }^{\ddagger}$ \\ School of Chemistry, Institute of Science, Suranaree University of Technology, Nakhon Ratchasima 30000, \\ Thailand, and Department of Theoretical Chemistry, Institute of General, Inorganic and Theoretical Chemistry, \\ University of Innsbruck, Innrain 52a, A-6020 Innsbruck, Austria
}

Received: July 26, 2006; In Final Form: September 22, 2006

\begin{abstract}
The structural and dynamical properties of $\mathrm{NO}_{3}{ }^{-}$in dilute aqueous solution have been investigated by means of two combined quantum mechanics/molecular mechanics (QM/MM) molecular dynamics simulations, namely $\mathrm{HF} / \mathrm{MM}$ and B3LYP/MM, in which the ion and its surrounding water molecules were treated at HF and B3LYP levels of accuracy, respectively, using the DZV+ basis set. On the basis of both HF and B3LYP methods, a well-defined first hydration shell of $\mathrm{NO}_{3}{ }^{-}$is obtainable, but the shell is quite flexible and the hydrogen-bond interactions between $\mathrm{NO}_{3}{ }^{-}$and water are rather weak. With respect to the detailed analysis of the geometrical arrangement and vibrations of $\mathrm{NO}_{3}{ }^{-}$, the experimentally observed solvent-induced symmetry breaking of the ion is well reflected. In addition, the dynamical information, i.e., the bond distortions and shifts in the corresponding bending and stretching frequencies as well as the mean residence time of water molecules surrounding the $\mathrm{NO}_{3}{ }^{-}$ion, clearly indicates the "structure-breaking" ability of this ion in aqueous solution. From a methodical point of view it seems that both the HF and B3LYP methods are not too different in describing this hydrated ion by means of a QM/MM simulation. However, the detailed analysis of the dynamics properties indicates a better suitability of the HF method compared to the B3LYP-DFT approach.
\end{abstract}

\section{Introduction}

Due to the key role ions play in many chemical and biological processes, ${ }^{1,2}$ a number of experimental and theoretical studies have been carried out to obtain detailed knowledge about ions in aqueous electrolyte solutions. ${ }^{3-5}$ Considering the structural feature of ions solvated in aqueous solution, cations usually have simple solvation geometries due to their relatively large binding energies between the cation and water. Unlike cations, anion solvation is more complicated since most of the anion-water interactions are generally weaker than those of cations and energetically comparable with the water-water interactions. As a consequence, a delicate balance between anion-water and water-water interactions is crucial in determining bulk vs surface solvation, i.e., structures with the anion on the "surface" of water clusters.

Nitrate anion $\left(\mathrm{NO}_{3}{ }^{-}\right)$is one of the important ions in solution chemistry and biology, which is frequently encountered as a terminal anion in the series of reactions involving nitrogen. ${ }^{6}$ In the gas phase, the isolated $\mathrm{NO}_{3}{ }^{-}$ion is nominally planar and has $D_{3 h}$ symmetry. In polar solvents, however, its $D_{3 h}$ symmetry is expected to be broken by the influence of solvent environment. These effects have already been explored via resonance Raman spectroscopy studies. ${ }^{7,8}$ Recently, the Raman spectra of aqueous solutions of $\mathrm{Mg}\left(\mathrm{NO}_{3}\right)_{2}$ have been reported, ${ }^{9}$ providing a detailed picture of the $\mathrm{NO}_{3}{ }^{-}$ion in different salt concentrations. In aqueous solution, the hydration shell structure of $\mathrm{NO}_{3}{ }^{-}$ has been studied both by experiments and computer simulations. Experimental studies, in particular neutron and X-ray diffrac-

* Corresponding author fax: 0066-44-224017; e-mail: anan_tongraar@ yahoo.com.

Suranaree University of Technology.

$\doteqdot$ University of Innsbruck. tions, $3,10,11$ have reported a wide variety of coordination numbers, ranging from about 2 to 18 . The observed large discrepancy has been attributed to the interference of counterions. In conjunction with experiments, computer simulations of aqueous solutions containing $\mathrm{NO}_{3}{ }^{-}$have provided structural and dynamical details of this solvated ion at molecular level.9,12-17 However, most of the early simulation works had relied on classical molecular mechanical models. It has been demonstrated that the hydration shell structure as well as the orientations of water molecules surrounding the ion depend quite sensitively on the interaction potentials employed in the simulations. ${ }^{16}$

As a result of the continuous increase in computer capacity and performance, more sophisticated molecular dynamics (MD) techniques based on a combined quantum mechanics/molecular mechanics (QM/MM) approach have become an elegant tool to elucidate microscopic details of solvation structure and dynamics of various ions in solution..$^{5,18-25}$ In the QM/MM approach, the most interesting region, a sphere which includes the ion and its surrounding solvent molecules, is treated quantum mechanically. By this scheme, the complicated many-body contributions as well as the polarization effects, which are hardly accessible through the basic assumptions underlying the classical models, can be reliably included into the specific region. For small anions, like $\mathrm{F}^{-}$and $\mathrm{Cl}^{-}$, our previous QM/MM studies have pointed out the importance of QM treatment for obtaining a realistic picture of these ions. ${ }^{5,19}$ For example, the QM/MM results clearly demonstrated a substantial decrease of the $\mathrm{F}^{-}$ coordination number compared to that predicted by pair potential simulation. In the case of $\mathrm{Cl}^{-}$, it has been shown that the orientation of first shell water molecules was considerably changed by quantum effects, although the pair potential simulation supplied an almost identical coordination number. In addition, with respect to detailed analysis on the dynamics of 
TABLE 1: Stabilization Energies and Some Selected Structural Parameters of the Optimized $\mathrm{NO}_{3}{ }^{-}-\mathrm{H}_{2} \mathrm{O} \mathrm{Complex}$ Calculated at HF, B3LYP, MP2, and CCSD Methods Using DZV+ and aug-cc-pvtz (Data in Parentheses) Basis Sets

\begin{tabular}{|c|c|c|c|c|}
\hline$\sum_{\mathrm{b} 3}^{\text {method }}$ & $\mathrm{HF}$ & B3LYP & MP2 & CCSD \\
\hline$\Delta E\left(\mathrm{kcal}^{\prime} \cdot \mathrm{mol}^{-1}\right)$ & $-16.43(-13.58)$ & $-18.60(-15.76)$ & $-16.83(-13.96)$ & $-16.78(-14.19)$ \\
\hline$R_{2-1}(\AA)$ & $1.275(1.224)$ & $1.315(1.263)$ & $1.333(1.265)$ & $1.330(1.252)$ \\
\hline$R_{2-3}(\AA)$ & $1.276(1.224)$ & $1.316(1.263)$ & $1.333(1.265)$ & $1.330(1.252)$ \\
\hline$R_{2-4}(\AA)$ & $1.259(1.212)$ & $1.296(1.247)$ & $1.318(1.251)$ & $1.308(1.239)$ \\
\hline$R_{1-7}(\AA)$ & $2.230(2.217)$ & $2.090(2.062)$ & $2.168(2.028)$ & $2.186(2.071)$ \\
\hline$R_{3-5}(\AA)$ & $2.211(2.219)$ & $2.078(2.071)$ & $2.152(2.039)$ & $2.171(2.055)$ \\
\hline$R_{6-5}(\AA)$ & $0.956(0.946)$ & $0.986(0.972)$ & $0.988(0.972)$ & $0.986(0.970)$ \\
\hline$R_{6-7}(\AA)$ & $0.956(0.946)$ & $0.986(0.972)$ & $0.988(0.972)$ & $0.986(0.970)$ \\
\hline$A_{5-6-7}(\mathrm{deg})$ & $105.87(99.94)$ & $102.30(97.13)$ & $103.22(95.81)$ & $103.39(96.60)$ \\
\hline$A_{1-7-6}(\mathrm{deg})$ & $135.11(138.76)$ & $138.61(141.93)$ & $137.82(143.15)$ & $137.59(141.21)$ \\
\hline$A_{3-5-6}(\mathrm{deg})$ & $136.52(138.61)$ & $139.43(141.22)$ & $139.07(142.17)$ & $138.81(142.52)$ \\
\hline
\end{tabular}

these hydrated ions, it has been proven that $\mathrm{F}^{-}$clearly acted as a "structure-maker", while the characteristics of $\mathrm{Cl}^{-}$solvation led to a more flexible structure with frequent rearrangements of the hydrogen bonds. ${ }^{20}$

With respect to the previous QM/MM studies for simple anions, it was our increased interest to apply the more accurate $\mathrm{QM} / \mathrm{MM}$ technique for studying more complicated anions, like $\mathrm{NO}_{3}{ }^{-}$. In the present study, therefore, two combined QM/MM MD simulations, namely HF/MM and B3LYP/MM, have been performed in order to obtain better knowledge about the solvation structure and dynamics of $\mathrm{NO}_{3}{ }^{-}$in water.

\section{Methods}

Details of the QM/MM MD technique have been reported elsewhere in the literature..$^{5,18-25}$ With regard to the QM/MM scheme, besides the statistical requirement of a sufficiently long simulation time, the selection of the QM method, basis set, and QM size is crucial for obtaining a correct description on the structural and dynamical properties of solvated ions. As a matter of fact, the performance of QM/MM MD simulations in conjunction with correlated ab initio methods is still too timeconsuming, making the $\mathrm{HF}$ and hybrid density functional B3LYP methods the possible alternatives for the present study. To simply test whether the HF or B3LYP methods are adequate for this particular system, geometry optimizations of the $\mathrm{NO}_{3}{ }^{-}-$ $\mathrm{H}_{2} \mathrm{O}$ complex were carried out at HF, B3LYP, MP2, and CCSD levels of accuracy (see Table 1). The comparison to the data obtained by correlated methods indicated that the HF and B3LYP methods both appear reliable enough to achieve a sufficient level of accuracy in the QM/MM simulations and that the correlation effects are small and thus negligible. As can be seen from the data in Table 1, the stabilization energies, which are the most relevant data determining solute-solvent interactions, are considerably overrated by the B3LYP method, independent of the basis set. On the other hand, the ion-ligand distances show better agreement between correlated ab initio methods and B3LYP within the same basis set quality, but the distances obtained by $\mathrm{HF}$ with the $\mathrm{DZV}+$ basis set to be employed in the QM/MM simulation are in fair agreement with the correlated distances obtained by the larger basis set and thus indicate this basis set to be a good compromise for the simulation if the HF method is used. The HF method has been well validated in previous $\mathrm{QM} / \mathrm{MM}$ studies, ${ }^{18-26}$ even for the treatment of anions, also proving the assumption that the effects of electron correlation are small enough to be neglected. ${ }^{19,20}$ In a recent $\mathrm{QM} / \mathrm{MM} \mathrm{MD}$ simulation of pure water, ${ }^{26}$ it has been demonstrated that the HF method with a sufficiently large QM size could provide detailed information of pure water in good agreement with the MP2-based simulation and with experimental data concerning H-bond structure and lifetime. The B3LYP method proved inferior in this case, but it was also employed in this work in order to test its adequacy for the description of hydrated anions, as several cases have shown that the DFT methods can give poor results for hydrated cations. ${ }^{5,24,25} \mathrm{It}$ should be realized that while the HF scheme could produce an error due to the neglect of electron correlation effects, the DFT methods, although including such effects to a certain (uncontrollable) extent, are often found to overestimate the correlation energy. ${ }^{23-26}$ On the other hand, a comparison of the HF calculations with the DFT results could be helpful to give a qualitative estimate of a possible influence of correlation effects.

In addition to the choice of the QM method, it is known that the use of a larger basis set is a key factor for obtaining better results (see Table 1). In practice, however, the computational expense for QM force calculations using large basis sets is significant. In most of the previous QM/MM studies, ${ }^{18-26}$ a moderate basis set has been employed, therefore. In the present work, since a satisfactory description of anions requires diffuse basis functions, the DZV+ basis set $^{27}$ was chosen, considered as a suitable compromise between the quality of the simulation results and the requirement of CPU time. To define the size of the $\mathrm{QM}$ region, a preliminary $\mathrm{HF} / \mathrm{MM}$ simulation, i.e., the simulation in which only the $\mathrm{NO}_{3}{ }^{-}$was treated quantum mechanically using the HF method while the rest of the system is described by classical pair potentials, was performed (see Figure 2a). According to the resulting $\mathrm{N}-\mathrm{O}_{\mathrm{w}}$ radial distribution function (RDF), the first minimum of the $\mathrm{N}-\mathrm{O}_{\mathrm{w}}$ peak is exhibited at around $5.0 \AA$. An integration up to the first minimum of the $\mathrm{N}-\mathrm{O}_{\mathrm{w}}$ peak yields about $18-20$ water molecules. This implies that a QM size with diameter of 10.0 $\AA$ seemed to be desirable for the present study. However, the evaluation of QM forces for all particles within this QM size is still beyond the limit of our current computational facility. Therefore, a slightly smaller QM size with diameter of $8.8 \AA$ was chosen, which includes $\mathrm{NO}_{3}{ }^{-}$and about $14-16$ water molecules.

To ensure a continuous change of forces at the boundary between the $\mathrm{QM}$ and $\mathrm{MM}$ regions, a smoothing function ${ }^{28}$ was employed within an interval of $0.2 \AA$ (i.e., between the N- - $\mathrm{O}_{\mathrm{w}}$ distances of 4.4-4.6 $\AA$ ). A flexible model, which describes intermolecular ${ }^{29}$ and intramolecular ${ }^{30}$ interactions, was employed for water. This flexible water model allows explicit hydrogen movements, thus ensuring a smooth transition, when water molecules move from the QM region with its full flexibility to 


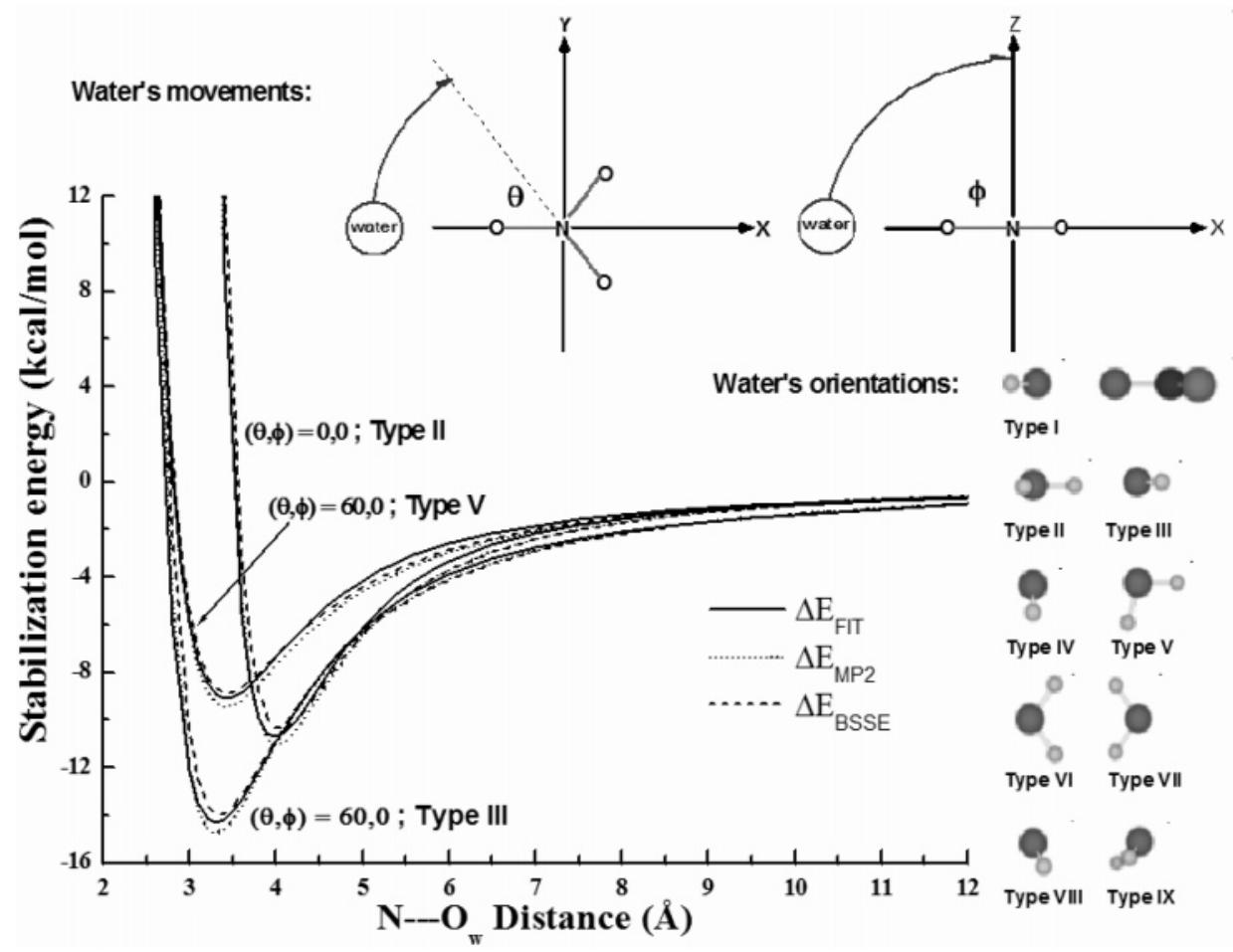

Figure 1. Comparison of the interaction energies obtained from the MP2 calculations with and without basis set superposition error (BSSE) correction, $\Delta E_{\mathrm{MP} 2}$ and $\Delta E_{\mathrm{BSSE}}$, and from the fitted potential function, $\Delta E_{\mathrm{FIT}}$, using the parameters given in Table 2 for some values of $\theta$ and $\phi$.

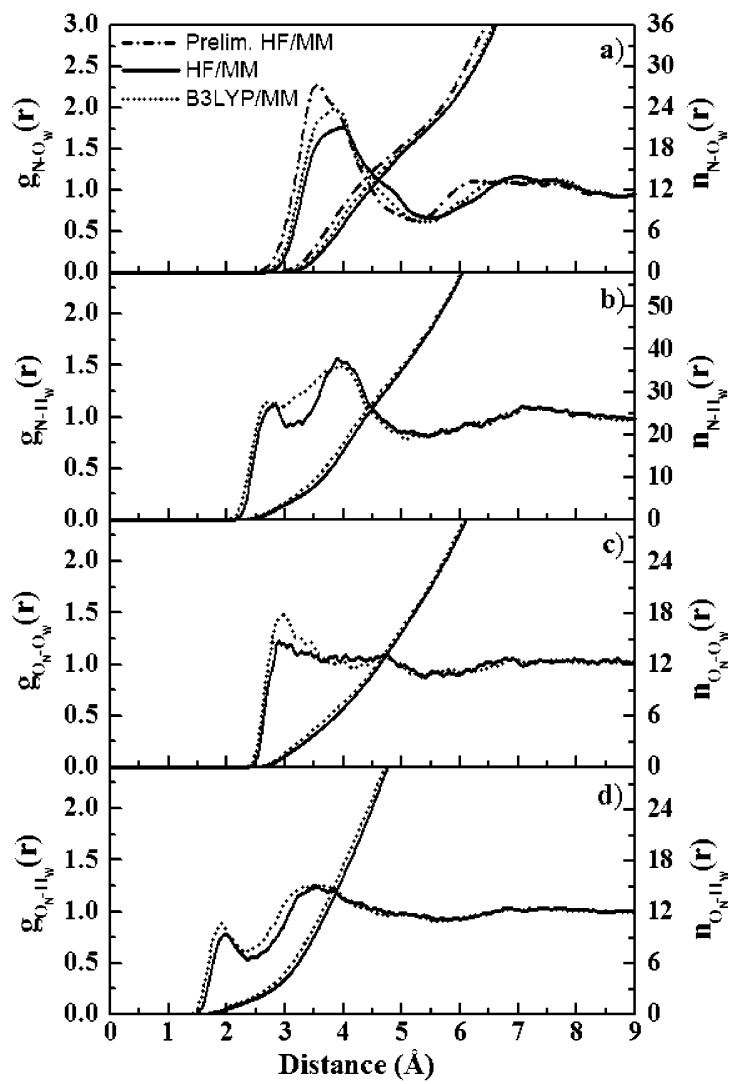

Figure 2. (a) $\mathrm{N}-\mathrm{O}_{\mathrm{w}}$, (b) $\mathrm{N}-\mathrm{H}_{\mathrm{w}}$, (c) $\mathrm{O}_{\mathrm{N}}-\mathrm{O}_{\mathrm{w}}$, and (d) $\mathrm{O}_{\mathrm{N}}-\mathrm{H}_{\mathrm{w}}$ radial distribution functions and their corresponding integration numbers.

the MM region. The pair potential function for $\mathrm{NO}_{3}{ }^{-}-\mathrm{H}_{2} \mathrm{O}$ interactions was newly constructed. The procedure is as follows: the $\mathrm{NO}_{3}{ }^{-}$ion was placed on the $x y$ plane (see Figure 1), while a water molecule was allowed to move with respect to
TABLE 2: Optimized Parameters of the Analytical Pair Potential for the Interaction of Water with $\mathrm{NO}_{3}-$ (Interaction Energies in $\mathrm{kcal} \cdot \mathrm{mol}^{-1}$ and Distances in $\stackrel{\AA}{\text { ) }}$

\begin{tabular}{cccrc}
\hline pair & $\begin{array}{c}\boldsymbol{A} \\
\left(\mathrm{kcal} \mathrm{mol}^{-1} \AA^{4}\right)\end{array}$ & $\begin{array}{c}\boldsymbol{B} \\
\left(\mathrm{kcal} \mathrm{mol}^{-1} \AA^{5}\right)\end{array}$ & $\begin{array}{c}\boldsymbol{C} \\
\left(\mathrm{kcal} \mathrm{mol}^{-1}\right)\end{array}$ & $\begin{array}{c}\boldsymbol{D} \\
\left(\AA^{-1}\right)\end{array}$ \\
\hline $\mathrm{N}-\mathrm{O}_{\mathrm{w}}$ & -1310.7757 & 10012.1163 & -55579.5941 & 2.8288 \\
$\mathrm{~N}-\mathrm{H}_{\mathrm{w}}$ & -512.0615 & 209.1700 & 5811.3787 & 2.9891 \\
$\mathrm{O}_{\mathrm{N}}-\mathrm{O}_{\mathrm{w}}$ & 332.9194 & 1807.6405 & -722.8225 & 1.2542 \\
$\mathrm{O}_{\mathrm{N}}-\mathrm{H}_{\mathrm{w}}$ & -84.1666 & 132.7195 & 53.9955 & 1.1110
\end{tabular}

the variation of $\theta$ (i.e., between 0 and $60^{\circ}$ ) and $\phi$ (i.e., between 0 and $90^{\circ}$ ), associated with 9 different types of water orientation. Then, a total of 5266 MP2 interaction energy points for various $\mathrm{NO}_{3}{ }^{-}-\mathrm{H}_{2} \mathrm{O}$ configurations, obtained from Gaussian98 ${ }^{31}$ calculations using the aug-cc-pvdz basis set, ${ }^{32-34}$ were fitted to an analytical form of

$$
\begin{aligned}
\Delta E_{\mathrm{NO}_{3}{ }^{-}-\mathrm{H}_{2} \mathrm{O}}= & \\
& \sum_{i=1}^{4} \sum_{j=1}^{3}\left[\frac{A_{i j}}{r_{i j}^{4}}+\frac{B_{i j}}{r_{i j}^{5}}+C_{i j} \exp \left(-D_{i j} r_{i j}\right)+\frac{q_{i} q_{j}}{r_{i j}}\right]
\end{aligned}
$$

where $A, B, C$, and $D$ are fitting parameters (see Table 2), $r_{i j}$ denotes the distances between the $i$ th atoms of $\mathrm{NO}_{3}{ }^{-}$and the $j$ th atoms of water molecule, and $q$ are atomic net charges. In the present study, the charges on $\mathrm{N}$ and $\mathrm{O}$ of $\mathrm{NO}_{3}{ }^{-}$were obtained from the Mulliken population analysis (MPA) of MP2 calculations using the aug-cc-pvdz basis set, and the charges on $\mathrm{O}$ and $\mathrm{H}$ of the water molecule were adopted from the flexible water model. ${ }^{30}$ They were set to $1.4996,-0.8332$, -0.6598 , and 0.3299 , respectively. It is known that the MPA certainly depends on the basis set. However, when fitting a potential function to an energy surface, the absolute values of the charges are only of secondary importance since the other parameters will compensate (i.e., as an energy surface is fitted, the $r^{-n}$ terms in the potential together with the Coulombic term 


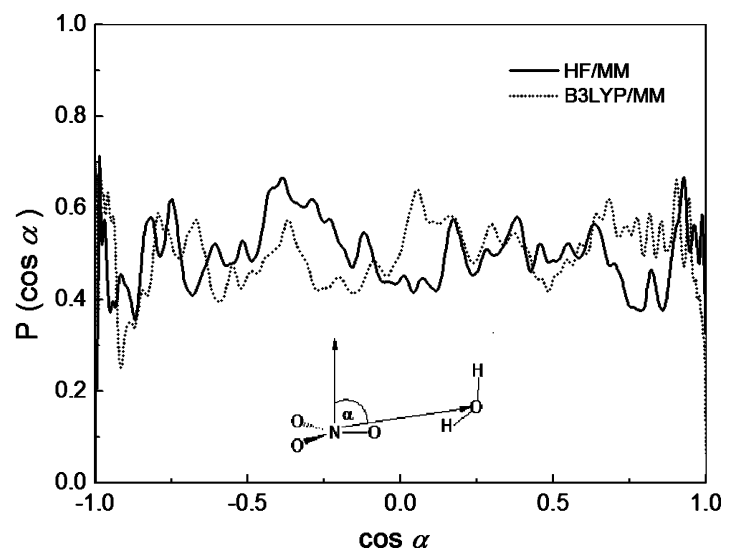

Figure 3. Distributions of the angle $\alpha$ between the vector perpendicular to the $\mathrm{NO}_{3}{ }^{-}$plane and the vector along the $\mathrm{N}---\mathrm{O}_{\mathrm{w}}$ distance, calculated within the first minimum of $\mathrm{N}-\mathrm{O}_{\mathrm{w}} \mathrm{RDFs}$.

are only an approximation to fit this surface). The quality of the fit is shown in Figure 1, where the stabilization energies obtained from the MP2 calculations $\left(\Delta E_{\mathrm{MP} 2}\right)$ and from the fitted potential function $\left(\Delta E_{\mathrm{FIT}}\right)$ are compared for some configurations. In Figure 1, the MP2 interaction energies with BSSE correction $\left(\Delta E_{\mathrm{BSSE}}\right)$ are also given for comparison. In this work, the counterpoise correction was not taken into consideration since the BSSE estimates suggest that a correction seems unnecessary.

All simulations were performed in a canonical ensemble at $298 \mathrm{~K}$ with a time step of $0.2 \mathrm{fs}$. The periodic box, with a box length of $18.17 \AA$, contained one $\mathrm{NO}_{3}{ }^{-}$and 199 water molecules, corresponding to the experimental density of pure water. Long-range interactions were treated using the reactionfield procedure. ${ }^{35}$ The system was initially equilibrated by performing a preliminary HF/MM MD simulation, in which only the $\mathrm{NO}_{3}{ }^{-}$was treated quantum mechanically using the $\mathrm{HF}$ method, for 200000 time steps. Then, the HF/MM and B3LYP/ MM simulations were started independently with the system's re-equilibration for 30000 time steps, followed by another 75000 (HF/MM) and 85000 (B3LYP/MM) time steps to collect configurations every 10th step.

\section{Results and Discussion}

3.1. Structural Details. The solvation structure of $\mathrm{NO}_{3}{ }^{-}$in water is described by means of $\mathrm{N}-\mathrm{O}_{\mathrm{w}}, \mathrm{N}-\mathrm{H}_{\mathrm{w}}, \mathrm{O}_{\mathrm{N}}-\mathrm{O}_{\mathrm{w}}$, and $\mathrm{O}_{\mathrm{N}}-\mathrm{H}_{\mathrm{w}}$ RDFs, together with their corresponding integration numbers, as shown in Figure 2. According to the shape and height of the resulting $\mathrm{N}-\mathrm{O}_{\mathrm{w}}$ RDFs (Figure 2a), both HF/MM and B3LYP/MM simulations reveal broad and unsymmetrical first $\mathrm{N}-\mathrm{O}_{\mathrm{w}}$ peaks with maximum at 3.96 and $3.83 \AA$, respectively. Integrations up to the first minimum of the corresponding $\mathrm{N}-\mathrm{O}_{\mathrm{w}}$ peaks yield average coordination numbers of 21.6 and 20.9 , respectively. The observed broad and unsymmetrical $\mathrm{N}-\mathrm{O}_{\mathrm{w}}$ RDFs clearly indicate a high flexibility of the $\mathrm{NO}_{3}{ }^{-}$ hydration shell. In addition, the first minimum of the $\mathrm{N}-\mathrm{O}_{\mathrm{w}}$ peaks is not well separated from the bulk, indicating a large number of water molecules situated between the hydration shell and bulk. This implies also that water molecules in the hydration shell of $\mathrm{NO}_{3}{ }^{-}$are quite mobile, i.e., they can easily exchange with bulk water. Comparing the corresponding $\mathrm{N}-\mathrm{O}_{\mathrm{w}} \mathrm{RDF}$ obtained by the preliminary HF/MM simulation (Figure 2a), it becomes obvious that the use of only classical $\mathrm{NO}_{3}{ }^{-}-\mathrm{H}_{2} \mathrm{O}$ and $\mathrm{H}_{2} \mathrm{O}-\mathrm{H}_{2} \mathrm{O}$ pair potentials is inadequate to correctly describe the short-range ion-water and water-water interactions, producing a higher rigidity of the $\mathrm{NO}_{3}{ }^{-}$hydration shell.

In Figure $2 b$, the $\mathrm{N}-\mathrm{H}_{\mathrm{w}} \mathrm{RDF}$ s obtained between the $\mathrm{HF} /$ $\mathrm{MM}$ and B3LYP/MM simulations are significantly different.

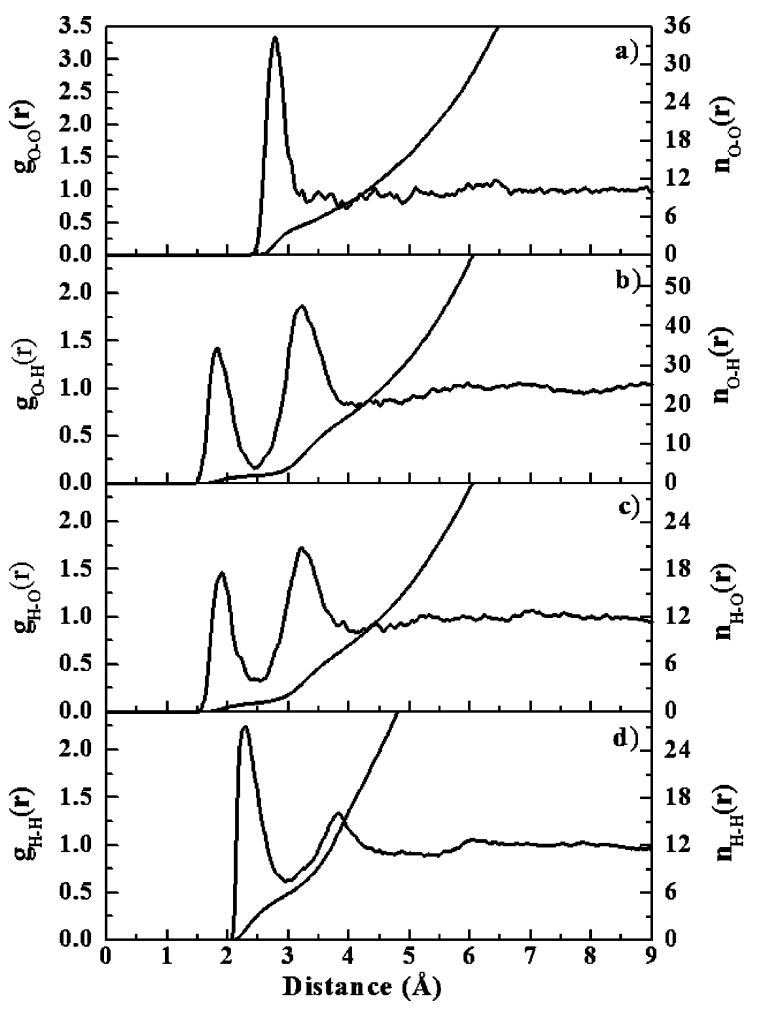

Figure 4. (a) $\mathrm{O}-\mathrm{O}$, (b) $\mathrm{O}-\mathrm{H}$, (c) $\mathrm{H}-\mathrm{O}$, and (d) $\mathrm{H}-\mathrm{H}$ radial distribution functions and their corresponding integration numbers. The first atom of each pair refers to the atoms of the water molecule, whose oxygen position was defined as the center of the QM region during the QM/MM simulation.

The HF/MM simulation depicts two distinct peaks with maxima at distances of 2.62 and $4.03 \AA$. In the B3LYP/MM simulation, the first $\mathrm{N}-\mathrm{H}_{\mathrm{w}}$ peak is merged into a rather broad second peak, indicating that water molecules with somewhat distorted hydrogen bonding to oxygen atoms of $\mathrm{NO}_{3}{ }^{-}$are the main constituents of the first hydration shell. In Figure 2c, the $\mathrm{O}_{\mathrm{N}}{ }^{-}$ $\mathrm{O}_{\mathrm{w}}$ RDFs obtained from both HF/MM and B3LYP/MM simulations do not show distinct minima after the first shell, suggesting that a clear determination of the first shell coordination number for each of the oxygen atoms of $\mathrm{NO}_{3}{ }^{-}$is not feasible. This also points at rather weak ion-water hydrogen bonds. Figure 3 shows the distributions of water molecules surrounding the ion as the distributions of the cosine of angle $\alpha$ between the vector perpendicular to $\mathrm{NO}_{3}{ }^{-}$plane and the vector along any $\mathrm{N}$ - - $\mathrm{O}_{\mathrm{w}}$ distance. Obviously, both HF/MM and B3LYP/MM simulations do not indicate specific features for the distribution of first shell water molecules, i.e., they are mostly arranged with respect to $\mathrm{N}-\mathrm{O}_{\mathrm{N}} \cdots \mathrm{H}_{\mathrm{w}}-\mathrm{O}_{\mathrm{w}}$ hydrogen bonds. The first shell waters prefer to coordinate to oxygen atoms of $\mathrm{NO}_{3}{ }^{-}$, rather than to the nitrogen atom from above and/or below the $\mathrm{NO}_{3}{ }^{-}$plane. In addition, it is expected that numerous possible arrangements, such as bifurcated hydrogen bonds as well as cyclic arrangements with two distorted hydrogen bonds, can temporarily be formed in aqueous solution.

More information on hydrogen bonds between $\mathrm{NO}_{3}{ }^{-}$and water can be obtained via the $\mathrm{O}_{\mathrm{N}}-\mathrm{H}_{\mathrm{w}}$ RDFs (Figure 2d). Since the characteristics of hydrogen bonds in pure solvent represent a most important reference, the corresponding atom-atom RDFs for pure water obtained at a similar QM/MM level of accuracy ${ }^{36}$ were utilized for comparison, as depicted in Figure 4. In this work, the HF/MM and B3LYP/MM simulations reveal first $\mathrm{O}_{\mathrm{N}}-$ $\mathrm{H}_{\mathrm{w}}$ peaks with maxima at 1.98 and $1.91 \AA$, respectively. These first $\mathrm{O}_{\mathrm{N}}-\mathrm{H}_{\mathrm{w}}$ peaks are indicative of the hydrogen bonds between 


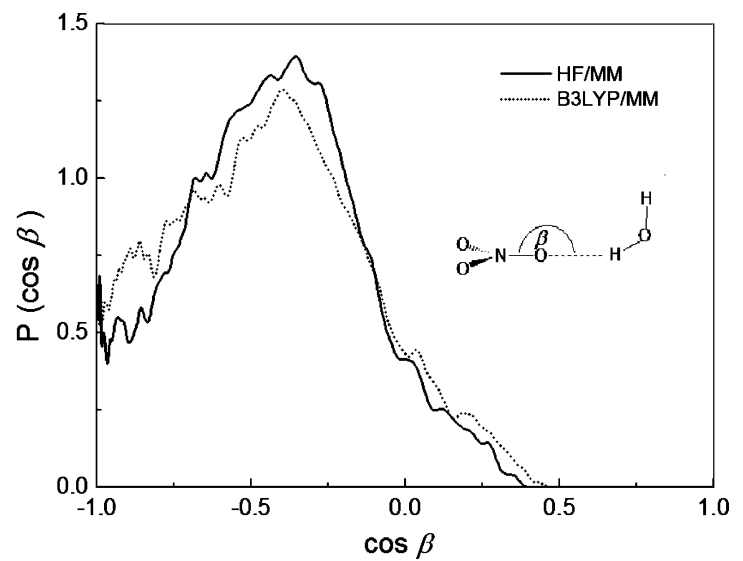

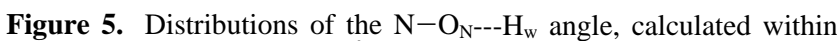
the $\mathrm{O}_{\mathrm{N}^{--}-\mathrm{H}_{\mathrm{w}}}$ distance of $2.5 \AA$.

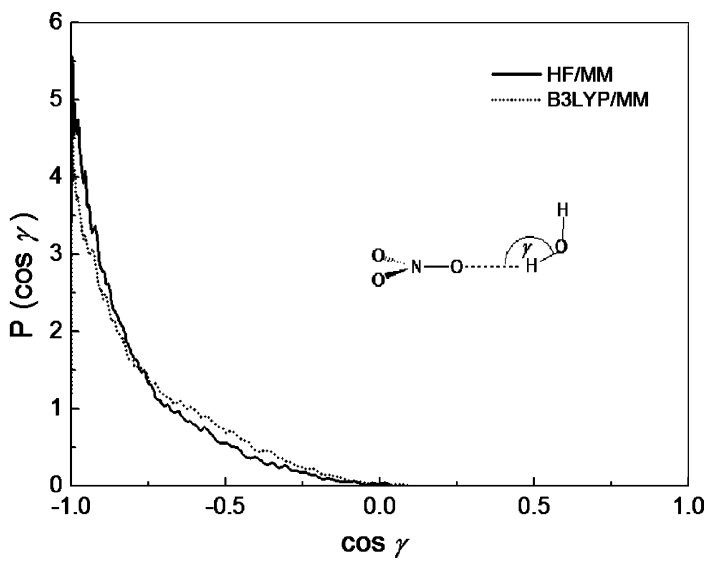

Figure 6. Distributions of the $\mathrm{O}_{\mathrm{N}^{--}-\mathrm{H}_{\mathrm{w}}}-\mathrm{O}_{\mathrm{w}}$ angle, calculated within the $\mathrm{O}_{\mathrm{N}^{--}-\mathrm{H}_{\mathrm{w}}}$ distance of $2.5 \AA$.

oxygen atoms of $\mathrm{NO}_{3}{ }^{-}$and their nearest-neighbor water molecules. Compared to the corresponding $\mathrm{O}-\mathrm{H}$ RDF of pure water (Figure 4), e.g., in terms of shape and peak height, it is obvious that the $\mathrm{O}_{\mathrm{N}} \cdots \mathrm{H}_{\mathrm{w}}-\mathrm{O}_{\mathrm{w}}$ hydrogen bond interactions are rather weak.

For a more detailed interpretation on the $\mathrm{NO}_{3}{ }^{-}$-water hydrogen bonds, the probability distributions of the cosine of the $\mathrm{N}-\mathrm{O}_{\mathrm{N}} \cdots \mathrm{H}_{\mathrm{w}}$ and $\mathrm{O}_{\mathrm{N}} \cdots \mathrm{H}_{\mathrm{w}}-\mathrm{O}_{\mathrm{w}}$ angles calculated from the subset of configurations within the $\mathrm{O}_{\mathrm{N}^{-}}--\mathrm{H}_{\mathrm{w}}$ distance of $2.5 \AA$ are plotted in Figures 5 and 6, respectively. For an ideal hydrogen bond, the $\mathrm{N}-\mathrm{O}_{\mathrm{N}} \cdot \mathrm{H}_{\mathrm{w}}-\mathrm{O}_{\mathrm{w}}$ interactions would be in a linear arrangement, i.e. a cosine equal or near to -1 for both $\mathrm{N}-\mathrm{O}_{\mathrm{N}} \cdots \mathrm{H}_{\mathrm{w}}$ and $\mathrm{O}_{\mathrm{N}} \cdots \mathrm{H}_{\mathrm{w}}-\mathrm{O}_{\mathrm{w}}$ angles. With respect to the results obtained by the HF/MM and B3LYP/MM simulations, the distributions of $\mathrm{N}-\mathrm{O}_{\mathrm{N}} \cdots \mathrm{H}_{\mathrm{w}}$ angles significantly deviate from linearity, whereas the distributions of the $\mathrm{O}_{\mathrm{N}}{ }^{\cdots} \mathrm{H}_{\mathrm{w}}-\mathrm{O}_{\mathrm{w}}$ angle show a clear preference for the linear $\mathrm{O}_{\mathrm{N}} \mathrm{H}_{\mathrm{w}}-\mathrm{O}_{\mathrm{w}}$ arrangements. Figure 7 shows the distributions of the cosine of the angle $\theta$, defined as the angle between the $\mathrm{O}_{\mathrm{w}^{-}}--\mathrm{O}_{\mathrm{N}}$ vector and the dipole vector of water molecules surrounding the $\mathrm{NO}_{3}{ }^{-}$oxygens. Apparently, both HF/MM and B3LYP/MM simulations show a clear dipole-oriented arrangement of water molecules surrounding the $\mathrm{NO}_{3}{ }^{-}$oxygens (e.g., the strong correlations between the nearest-neighbor water molecules and their lone pair direction), with maxima at $\cos \theta$ between 0.5 and 0.8 . It is obvious that despite the fact that the interactions between $\mathrm{NO}_{3}{ }^{-}$ and water are rather weak, the $\mathrm{O}_{\mathrm{w}}-\mathrm{H}_{\mathrm{w}} \cdots \mathrm{O}_{\mathrm{N}}$ bonds have a determining influence on the structure of hydrated $\mathrm{NO}_{3}{ }^{-}$.

3.2. Dynamical Details. 3.2.1. Intramolecular Geometry and Vibrations of $\mathrm{NO}_{3}{ }^{-}$. The geometrical arrangement of $\mathrm{NO}_{3}{ }^{-}$

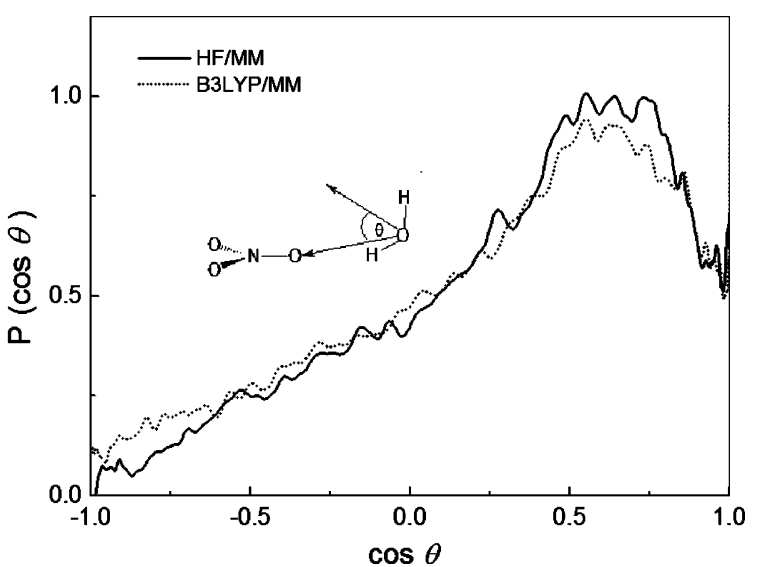

Figure 7. Distributions of the angle $\theta$ between the $\mathrm{O}_{\mathrm{w}^{---}} \mathrm{O}_{\mathrm{N}}$ vector and the vector of water's dipole moment, calculated within the $\mathrm{O}_{\mathrm{N}^{---}}$ $\mathrm{H}_{\mathrm{w}}$ distance of $2.5 \AA$.

in water is described in terms of distributions of the $\mathrm{N}-\mathrm{O}$ bond length and the $\mathrm{O}-\mathrm{N}-\mathrm{O}$ angle, as shown in Figure 8 (parts a and $b$, respectively). Both HF/MM and B3LYP/MM simulations clearly indicate a flexibility of the $\mathrm{NO}_{3}{ }^{-}$structure, with halfheight widths of about $1.26 \pm 0.05$ and $1.31 \pm 0.06 \AA$ for the distributions of $\mathrm{N}-\mathrm{O}$ bonds and of about $120 \pm 4$ and $120 \pm$ $5^{\circ}$ for the distributions of $\mathrm{O}-\mathrm{N}-\mathrm{O}$ angles, respectively. The observed difference between the HF/MM and B3LYP/MM simulations can probably be regarded more as a consequence of the approximations of the functional and the parametrizations of the B3LYP method than as a consequence of correlation effects. The results obtained by both the HF/MM and B3LYP/ MM simulations obviously suggest a substantial change in the local structure of $\mathrm{NO}_{3}{ }^{-}$, being either planar or nonplanar geometry with equivalent and/or inequivalent $\mathrm{N}-\mathrm{O}$ bonds, according to the influence of water environment. A useful indicator of the $\mathrm{NO}_{3}{ }^{-}$planarity in aqueous solution is the distribution of the angle $\phi$, defined by a vector along any $\mathrm{N}-\mathrm{O}$ bond and a vector pointing outward between the other two $\mathrm{N}-\mathrm{O}$ bonds, as shown in Figure 9, which illustrates that the intramolecular geometry of $\mathrm{NO}_{3}{ }^{-}$is slightly deviating from planarity, obviously because water molecules in the first hydration shell of $\mathrm{NO}_{3}{ }^{-}$oxygens break the $D_{3 h}$ symmetry of the ion.

The power spectra, which correspond to symmetric stretching $\left(v_{1}\right)$, out-of-plane bending $\left(v_{2}\right)$, asymmetric stretching $\left(v_{3}\right)$, and asymmetric bending $\left(v_{4}\right)$ vibrations, of $\mathrm{NO}_{3}{ }^{-}$were evaluated using normal-coordinate analysis. ${ }^{37}$ By Fourier transformations of three components of oxygen's velocity autocorrelation functions (VACFs), the corresponding $v_{1}, v_{2}, v_{3}$, and $v_{4}$ bands can be obtained, as summarized in Table 3. In this work, all calculated frequencies were multiplied by the standard scaling factors $^{38}$ of 0.9051 and 0.9614 for HF and B3LYP methods, respectively. With respect to the spectral data in Table 3, both HF/MM and B3LYP/MM simulations produce all four vibrational modes, with spectral frequencies in the order $v_{3}>v_{1}>$ $v_{2}>v_{4}$. The B3LYP/MM simulation produces the power spectra at lower frequencies than the HF/MM run. This corresponds to the observed higher flexibility of the $\mathrm{NO}_{3}{ }^{-}$structure (see Figures 8 and 9). In a qualitative sense, all frequencies obtained by both HF/MM and B3LYP/MM simulations are in reasonable agreement with the experimental data ${ }^{40,41}$ In this context, it should be noted that most of the experimental measurements for spectral analysis on $\mathrm{NO}_{3}{ }^{-}$have to be performed with solutions of relatively high concentrations, whereas the present HF/MM and B3LYP/MM results refer to dilute solution. 

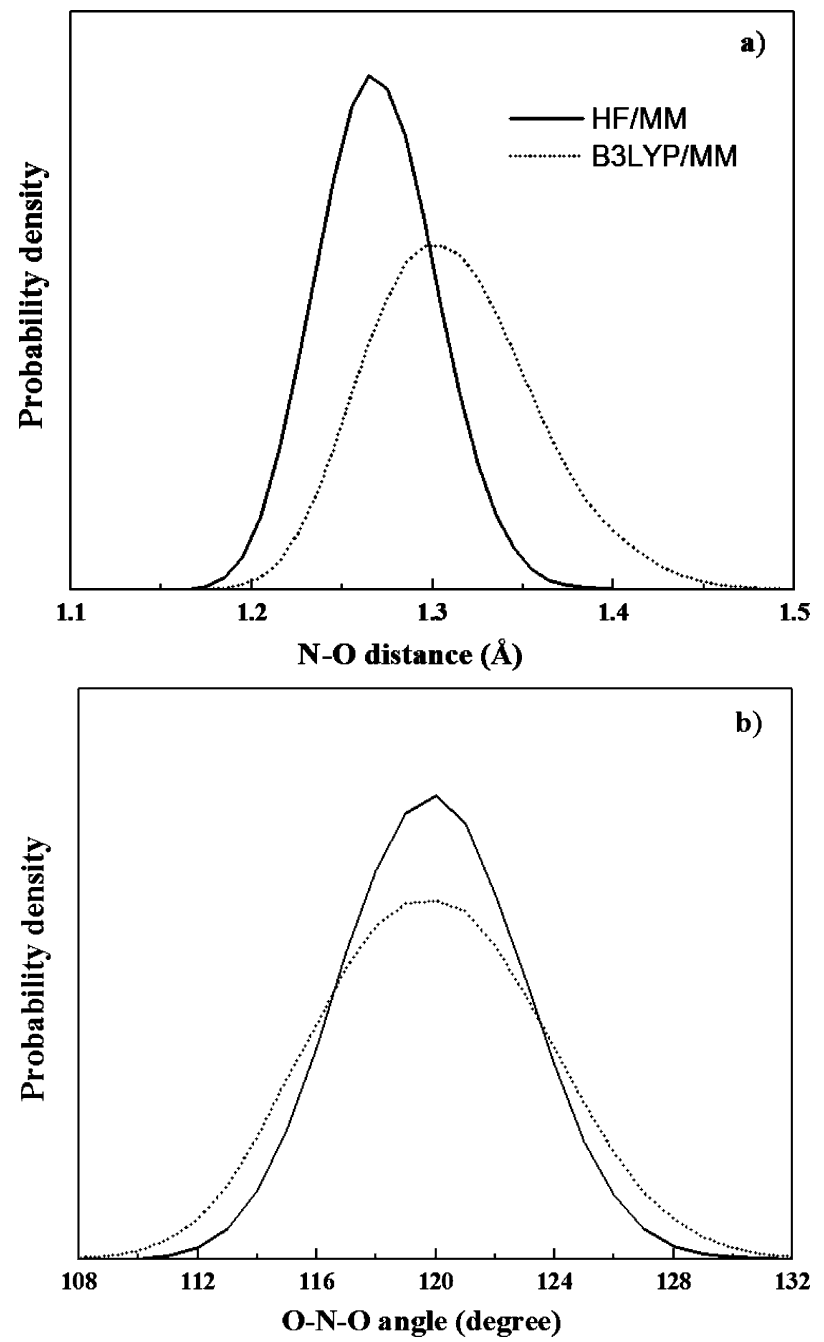

Figure 8. Distributions of (a) the $\mathrm{N}-\mathrm{O}$ bond length and (b) the $\mathrm{O}-\mathrm{N}-\mathrm{O}$ angle of $\mathrm{NO}_{3}{ }^{-}$.

An interesting feature of the vibrational frequencies of $\mathrm{NO}_{3}{ }^{-}$ is the experimentally observed $v_{3}$ splitting in aqueous solutions. According to the experimental observations, ${ }^{7,8,40}$ the $v_{3}$ asymmetric $\mathrm{N}-\mathrm{O}$ stretching mode was found to consist of two distinctive peaks corresponding to the decrease of local symmetry of $\mathrm{NO}_{3}{ }^{-}$, i.e., from $D_{3 h}$ to $C_{2 v}$ (or lower), due to its interaction with surrounding water molecules. In this work, the splitting of the $v_{3}$ band is well reflected, being about 40 and 24 $\mathrm{cm}^{-1}$ for HF/MM and B3LYP/MM simulations, respectively. In addition, in both simulations, the $v_{2}$ mode is less pronounced. This frequency mode is usually related to the change in the equilibrium geometry of $\mathrm{NO}_{3}{ }^{-}$from planar to pyramidal upon electronic excitation. ${ }^{7}$ In this context, the observed low intensity of $v_{2}$ bands can be attributed to the fact that the structure of $\mathrm{NO}_{3}{ }^{-}$in aqueous solution is not too far from planarity (see Figure 9). This finding is inconsistent with the lack of intensity of the out-of-plane deformation band in the resonance Raman spectrum of hydrated $\mathrm{NO}_{3}{ }^{-7}$.

3.2.2. Intramolecular Geometry and Vibrations of Water Molecules in the Hydration Shell of $\mathrm{NO}_{3}{ }^{-}$. The intramolecular geometry of water molecules in the bulk and in the vicinity of $\mathrm{NO}_{3}{ }^{-}$is explained in terms of distributions of $\mathrm{O}-\mathrm{H}$ bond length and $\mathrm{H}-\mathrm{O}-\mathrm{H}$ angle, as shown in Figure 10 (parts a and $\mathrm{b}$, respectively). The B3LYP/MM simulation shows longer $\mathrm{O}-\mathrm{H}$ bond lengths together with narrower $\mathrm{H}-\mathrm{O}-\mathrm{H}$ angles compared to the HF/MM results, with half-height widths of $0.98 \pm 0.035$ and $0.96 \pm 0.03 \AA$ for the distributions of $\mathrm{O}-\mathrm{H}$ bonds and of

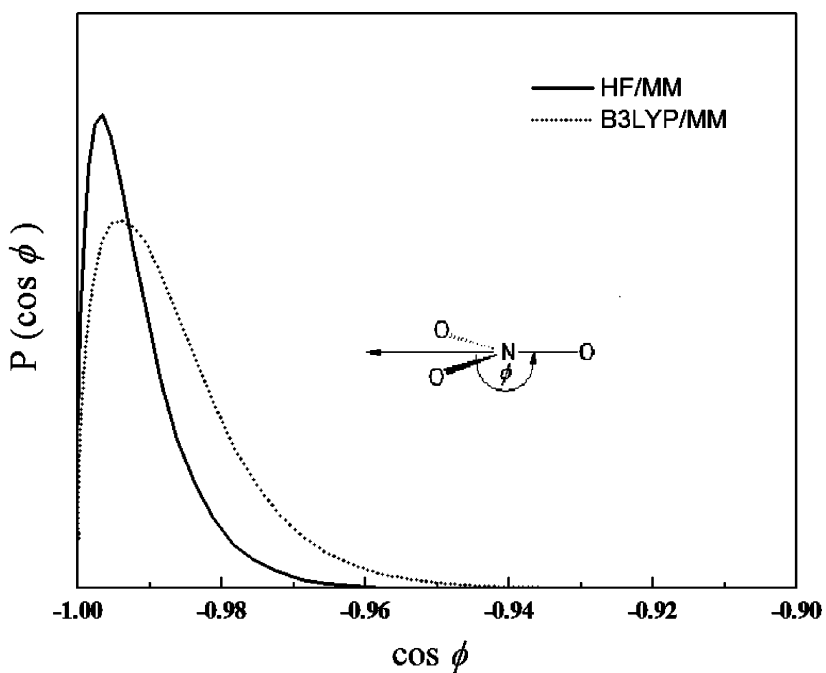

Figure 9. Distributions of $\phi$, as defined by a vector along any $\mathrm{N}-\mathrm{O}$ bond and a vector pointing outwards between the other two $\mathrm{N}-\mathrm{O}$ bonds.

TABLE 3: Vibrational Frequencies of $\mathrm{NO}_{3}{ }^{-}$

\begin{tabular}{lllll}
\hline \multirow{2}{*}{\multicolumn{1}{c}{ method }} & \multicolumn{4}{c}{ frequencies $\left(\mathrm{cm}^{-1}\right)$} \\
\cline { 2 - 5 } & \multicolumn{1}{c}{$v_{1}$} & \multicolumn{1}{c}{$v_{2}$} & \multicolumn{1}{c}{$v_{3}$} & \multicolumn{1}{c}{$v_{4}$} \\
\hline HF/MM MD & 1088 & 712 & 1401,1441 & 709 \\
B3LYP/MM MD & 965 & 710 & 1237,1313 & 649 \\
classical MD & 1009 & 814,833 & 1380,1393 & 704 \\
classical MD $^{16}$ & 996 & 816 & 1379 & 689 \\
MP4 (gas phase) & 996 & 816 & 1379 & 689 \\
B3LYP (gas phase) & 1061 & 844 & 1364 & 707 \\
experiments $^{40,41}$ & 1049 & 825 & 1348,1404 & 719 \\
& & & 1340,1460 & 720,740
\end{tabular}

$103 \pm 8$ and $110 \pm 6.5^{\circ}$ for the distributions of $\mathrm{H}-\mathrm{O}-\mathrm{H}$ angles, respectively. These differences can be a consequence of the higher coordination numbers resulting from the B3LYP/MM simulation, which will be discussed later.

With respect to the normal-coordinate analyses, ${ }^{37}$ the three quantities, $Q_{1}, Q_{2}$, and $Q_{3}$, calculated from the VACFs of water's hydrogens for describing symmetric stretching and bending and asymmetric stretching motions, respectively, are reported in Table 4. To reliably describe the effect of $\mathrm{NO}_{3}{ }^{-}$on the vibrational motions of its surrounding water molecules, the corresponding data for pure water obtained from previous $\mathrm{HF}$ / $\mathrm{MM}^{36}$ and B3LYP/MM ${ }^{43}$ simulations are given for comparison. In the HF/MM simulation, the bending and stretching frequencies of water molecules in the hydration shell of $\mathrm{NO}_{3}{ }^{-}$are slightly blue-shifted, by about 23,3 , and $15 \mathrm{~cm}^{-1}$ for $Q_{2}, Q_{1}$, and $Q_{3}$, respectively. The observed small changes in both the bending and stretching modes can be ascribed to a slight influence of $\mathrm{NO}_{3}{ }^{-}$on the vibrational motions of its surrounding water molecules. In the B3LYP/MM simulation, the corresponding $Q_{2}$ mode is blue-shifted by $15 \mathrm{~cm}^{-1}$, while the $Q_{1}$ and $Q_{3}$ show significant red-shifts of 187 and $25 \mathrm{~cm}^{-1}$, respectively. These data are in good accord with a generally more rigid structure of hydrated $\mathrm{NO}_{3}{ }^{-}$resulting from the DFT approach, which generally tends to exaggerate the strength of hydrogen bonds. ${ }^{42,43}$

3.2.3. Translational Motion and Exchange Process of Water Molecules in the Hydration Shell of $\mathrm{NO}_{3}{ }^{-}$. The selfdiffusion coefficients $(D)$ for water molecules in the bulk and in the hydration sphere of $\mathrm{NO}_{3}{ }^{-}$were calculated from the water's center-of-mass VACFs using the Green-Kubo relation ${ }^{47}$

$$
D=\frac{1}{3} \lim _{t \rightarrow \infty} \int_{0}^{t} C_{v}(t) \mathrm{d} t
$$


TABLE 4: Vibrational Frequencies of Water Molecules in the Bulk and in the Hydration Sphere of $\mathrm{NO}_{3}{ }^{-c}$

\begin{tabular}{cccc}
\hline $\begin{array}{c}\text { vibrations } \\
\left(\mathrm{cm}^{-1}\right)\end{array}$ & $\begin{array}{c}\text { hydration } \\
\text { shell of } \mathrm{NO}_{3}{ }^{-}\end{array}$ & bulk $^{a}$ & $\mathrm{H}_{2} \mathrm{O}(\mathrm{expt})^{b}$ \\
\hline$Q_{2}$ & $1661(1637)$ & $1638,{ }^{36} 1640^{42,43}(1622)^{43}$ & $1645,{ }^{44} 1643^{45}$ \\
$Q_{1}$ & $3566(3393)$ & $3563,{ }^{36} 3770,{ }^{42} 3774^{43}(3580)^{43}$ & 3345,44 \\
$Q_{3}$ & $3691(3528)$ & $3676,{ }^{36} 3775,{ }^{42} 37733^{43}(3553)^{43}$ & $3445^{44}$
\end{tabular}

${ }^{a}$ Values obtained from previous HF/MM and B3LYP/MM (i.e., numbers in parentheses) MD simulations of pure water using DZV (ref 36) and DZP (refs 42 and 43 ) basis sets. ${ }^{b}$ Experimental values of liquid water. ${ }^{c}$ Numbers in parentheses correspond to the data obtained by B3LYP/MMbased simulations.
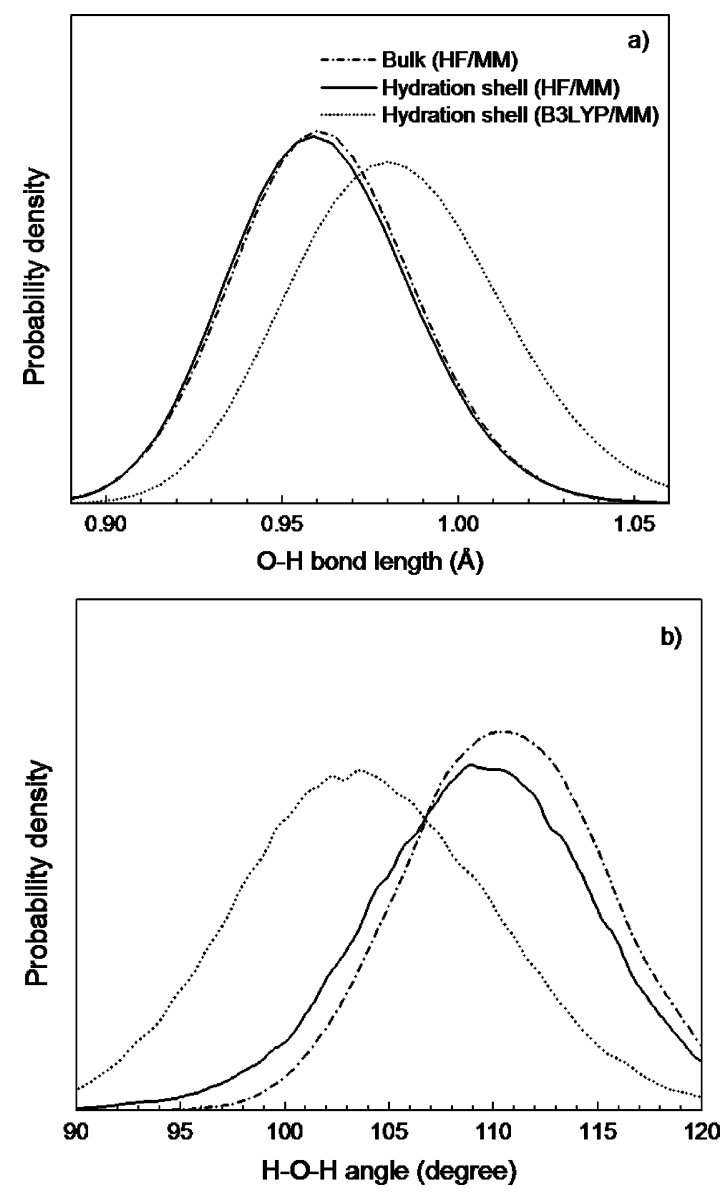

Figure 10. Distributions of (a) the $\mathrm{O}-\mathrm{H}$ bond length and (b) the $\mathrm{H}-\mathrm{O}-\mathrm{H}$ angle of water molecules in the bulk and in the hydration shell of $\mathrm{NO}_{3}^{-}$.

TABLE 5: Diffusion Coefficients of Water Molecules in the Bulk and in the Hydration Shell of $\mathrm{NO}_{3}{ }^{-}$

\begin{tabular}{lll}
\hline method & $\begin{array}{l}\text { hydration shell of } \mathrm{NO}_{3}^{-} \\
\left(\times 10^{-5} \mathrm{~cm}^{2} \mathrm{~s}^{-1}\right)\end{array}$ & $\begin{array}{l}\text { bulk } \\
\left(\times 10^{-5} \mathrm{~cm}^{2} \mathrm{~s}^{-1}\right)\end{array}$ \\
HF/MM MD & 5.09 & $3.31^{36}$ \\
B3LYP/MM MD & 4.14 & \\
experiment & & $2.30^{48}$
\end{tabular}

All of the calculated $D$ values are summarized in Table 5. In comparison to the data for bulk water obtained by a compatible QM/MM simulation, ${ }^{36}$ the $D$ values obtained from the HF/MM and B3LYP/MM simulations clearly indicate a high mobility of water molecules in the vicinity of $\mathrm{NO}_{3}{ }^{-}$. This phenomenon is inconsistent with the observed high flexibility of the $\mathrm{NO}_{3}{ }^{-}-$ water complex because of the weak ion-water interactions.

According to the $\mathrm{N}-\mathrm{O}_{\mathrm{w}}$ (Figure 2a) and the $\mathrm{O}_{\mathrm{N}}-\mathrm{O}_{\mathrm{w}}$ RDFs (Figure 2c), the nonzero first minimum of the RDFs obtained in both HF/MM and B3LYP/MM simulations suggests an easy exchange of water molecules in the vicinity of $\mathrm{NO}_{3}{ }^{-}$. Numerous water exchange processes, following either associative $(A)$ or

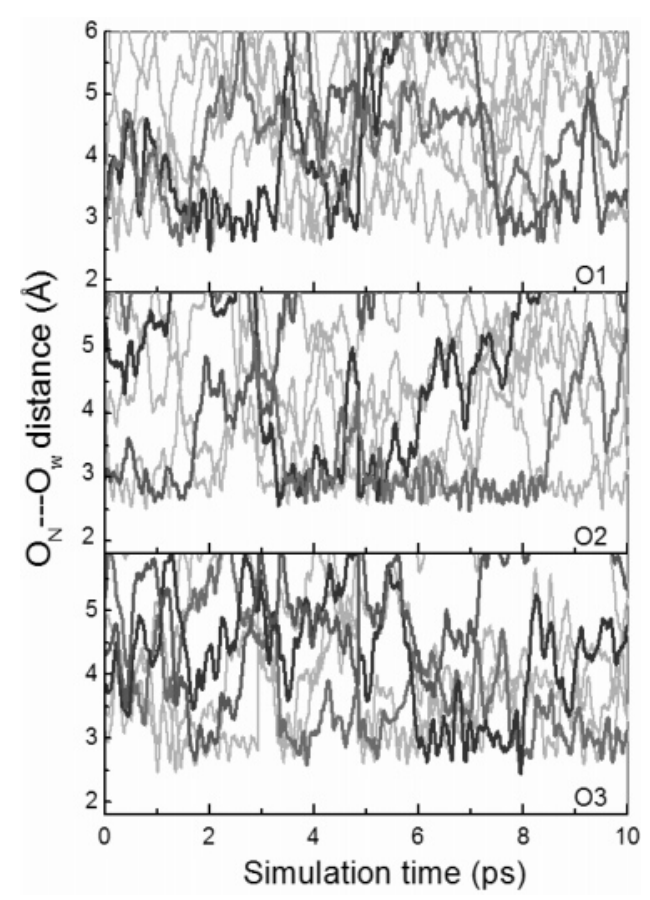

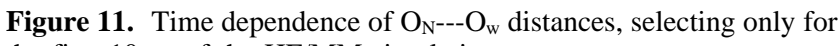
the first $10 \mathrm{ps}$ of the HF/MM simulation.

dissociative $(D)$ as well as associative $\left(I_{\mathrm{a}}\right)$ and dissociative $\left(I_{\mathrm{d}}\right)$ interchange mechanisms, were indeed observed when the $\mathrm{O}_{\mathrm{N}^{-}}-$$\mathrm{O}_{\mathrm{w}}$ distances were plotted against simulation time for the $\mathrm{HF} /$ MM and B3LYP/MM simulations, as shown in Figures 11 and 12 , respectively. The variability of water exchange process mechanisms observed can be considered as indication toward weak ion-water hydrogen bond interactions.

The rate of water exchange processes at each of the $\mathrm{NO}_{3}{ }^{-}$ oxygens was evaluated via mean residence times (MRT) of the water molecules. In this work, the MRT data were calculated using the direct method, ${ }^{49}$ as the product of the average number of nearest-neighbor water molecules located within the $\mathrm{O}_{\mathrm{N}^{-}}-$$\mathrm{O}_{\mathrm{w}}$ distance of $3.5 \AA$ with the duration of the simulation, divided by the number of exchange events. Since the $\mathrm{O}_{\mathrm{N}}-\mathrm{O}_{\mathrm{w}} \mathrm{RDFs}$ are less pronounced (see Figure 2c), the $\mathrm{O}_{\mathrm{N}^{-}}--\mathrm{O}_{\mathrm{w}}$ distance of $3.5 \AA$ was selected, assuming to be a rough estimate of the first minimum of $\mathrm{O}_{\mathrm{N}}-\mathrm{O}_{\mathrm{w}}$ RDFs and a limit for a significantly stabilizing anion-water interaction. Applying this evaluation limit, significantly different coordination numbers result from HF and B3LYP framework: while the HF method predicts average coordination numbers of $3.74-3.78$ for the oxygens, the same data for the B3LYP method are 4.75-4.99 (cf. Table 6 ). While all other data reported so far could be considered similar for both methods, these coordination numbers make a significant difference for the structure of the hydrated anion. Following the reported tendency of DFT methods to overestimate hydrogen bonding, the HF values are considered to be more reliable, but a better evaluation of this assumption appears only possible by a substantial increase of the QM diameter to 


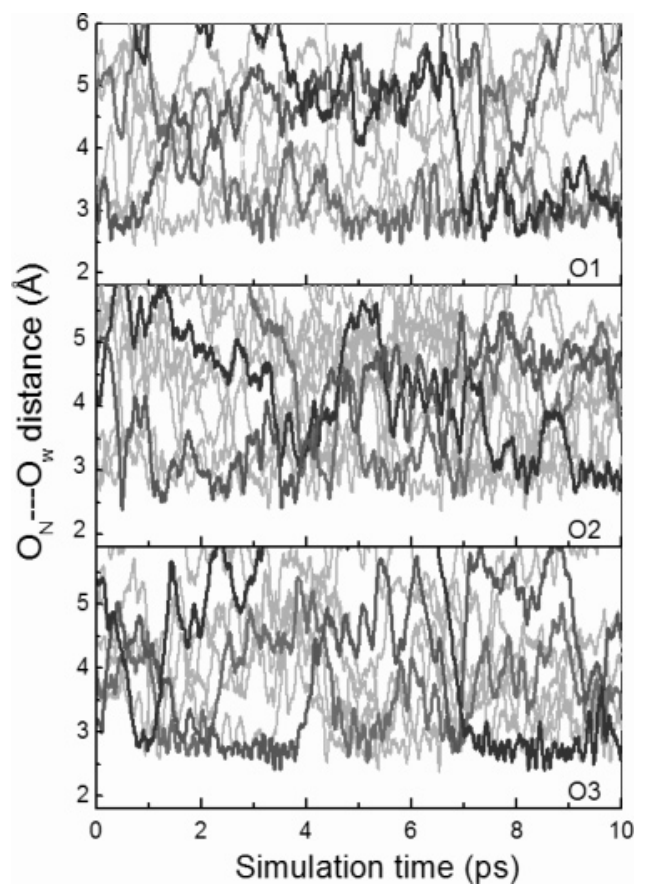

Figure 12. Time dependence of $\mathrm{O}_{\mathrm{N}^{--}-\mathrm{O}_{\mathrm{w}}}$ distances, selecting only for the first $10 \mathrm{ps}$ of the B3LYP/MM simulation.

TABLE 6: Mean Residence Time of Water Molecules in the Bulk and in the Vicinity of $\mathrm{NO}_{3}^{-}$Oxygens, Calculated within the $\mathrm{O}_{\mathrm{N}^{-}}-\mathrm{O}_{\mathrm{w}}$ Distance of $3.5 \AA$

\begin{tabular}{|c|c|c|c|c|c|c|}
\hline \multirow[b]{2}{*}{ atom/solute } & \multirow[b]{2}{*}{$\mathrm{CN}$} & \multirow[b]{2}{*}{$t_{\mathrm{sim}}$} & \multicolumn{2}{|c|}{$t^{*}=0.0 \mathrm{ps}$} & \multicolumn{2}{|c|}{$t^{*}=0.5 \mathrm{ps}$} \\
\hline & & & $N_{\mathrm{ex}}{ }^{0.0}$ & $\tau_{\mathrm{H}_{2} \mathrm{O}} 0.0$ & $N_{\mathbf{e x}}^{0.5}$ & $\tau_{\mathrm{H}_{2}}{ }^{0.5}$ \\
\hline \multicolumn{7}{|c|}{ HF/MM MD } \\
\hline $\mathrm{O} 1$ & 3.76 & 15.0 & 492 & 0.11 & 44 & 1.28 \\
\hline $\mathrm{O} 2$ & 3.74 & 15.0 & 464 & 0.12 & 39 & 1.44 \\
\hline $\mathrm{O} 3$ & 3.84 & 15.0 & 498 & 0.11 & 47 & 1.26 \\
\hline pure $\mathrm{H}_{2} \mathrm{O}^{36}$ & 4.6 & 12.0 & 292 & 0.2 & 31 & 1.8 \\
\hline pure $\mathrm{H}_{2} \mathrm{O}^{43}$ & 4.2 & 40.0 & & 0.33 & & 1.51 \\
\hline \multicolumn{7}{|c|}{ B3LYP/MM MD } \\
\hline $\mathrm{O} 1$ & 4.77 & 17.0 & 554 & 0.15 & 52 & 1.56 \\
\hline $\mathrm{O} 2$ & 4.99 & 17.0 & 613 & 0.14 & 61 & 1.39 \\
\hline $\mathrm{O} 3$ & 4.75 & 17.0 & 562 & 0.14 & 59 & 1.37 \\
\hline pure $\mathrm{H}_{2} \mathrm{O}^{43}$ & 4.2 & 30.0 & & 1.07 & & 7.84 \\
\hline
\end{tabular}

a value including a second shell of water molecules, thus including also hydrogen bonding between ligands and bulk into the same quantum mechanical description. Such an evaluation will be performed, when the necessary computational facilities will be available.

With respect to time parameters $t^{*}$ (i.e., the minimum duration of a ligand's displacement from its original coordination shell to be accounted) of 0.0 and $0.5 \mathrm{ps}$, the calculated MRT values are summarized in Table 6. In general, the MRT data obtained using $t^{*}=0.0 \mathrm{ps}$ are used for an estimation of hydrogen bond lifetimes, whereas the data obtained with $t^{*}=0.5 \mathrm{ps}$ are considered as a good estimate for sustainable ligand exchange processes. ${ }^{49}$ In this work, $\tau_{\mathrm{H}_{2} \mathrm{O}}\left(\mathrm{O}_{\mathrm{i}}\right)<\tau_{\mathrm{H}_{2} \mathrm{O}}\left(\mathrm{H}_{2} \mathrm{O}\right)$ results from both the HF/MM and B3LYP/MM simulations, without much differences in the values. However, as can be seen in Table 6, the previous $\mathrm{B} 3 \mathrm{LYP} / \mathrm{MM}$ simulation $^{43}$ of pure water had predicted much too slow exchange rates (while the HF values are close to the experimental values), proving the overestimation of hydrogen-bond strength by the B3LYP method. Hence, the anion-induced MRT differences obtained from the B3LYP/MM results are surely correct for the description but most probably too high in the amount. All MRT values obtained in both simulations make it obvious, however, that water molecules binding to $\mathrm{NO}_{3}{ }^{-}$oxygens are quite labile and that the hydrogen bonds between $\mathrm{NO}_{3}{ }^{-}$and water are weak, thus enabling very frequent water exchange processes within the hydration sphere of $\mathrm{NO}_{3}{ }^{-}$. The observed differences between the MRT values of the $\mathrm{NO}_{3}{ }^{-}$oxygens are related to the solvation structure of $\mathrm{NO}_{3}{ }^{-}$. On the other hand, this also implies that the time of simulation may not sufficient for a complete sampling of all possible structures at each of these oxygens. However, the variation width is small enough to assume reliability of the average value.

The MRT data are characteristic for a "structure-breaking" substance, and the ability of $\mathrm{NO}_{3}{ }^{-}$to act as structure-breaker in aqueous solution is also in accordance with all the previously reported data from our simulations.

\section{Conclusion}

The QM/MM MD simulations of this work have once more shown the capability of this approach in providing details of solvation structure and dynamics of ions, in this case specifically for the weakly interacting $\mathrm{NO}_{3}{ }^{-}$in dilute aqueous solution. Comparing the HF and B3LYP methods for the QM part of the system, most of the structural and dynamical data appear rather similar at a first glance, but coordination numbers and dynamical data finally indicate a certain superiority of the ab initio HF formalism. Possible weaknesses of the B3LYP scheme could be attributed to the incompleteness of the kinetic energy term, the self-interaction error, and the parametrization of the B3LYP method which did not contain any H-bonded system. The vibrations of $\mathrm{NO}_{3}{ }^{-}$clearly reflect the experimentally observed solvent-induced symmetry breaking of this ion in aqueous solution. The anion forms a distinct but very loosely bound first hydration shell, based on weak nitrate oxygen-water hydrogen bonds. The lability of this shell results in frequent exchanges of water molecules and causes a typical structure-breaking behavior of this ion in aqueous solution. When computational facilities allow, a further improvement of the quantitative values can be expected from extending the size of the QM region as well as from using ab initio correlated methods.

Acknowledgment. This work was supported by the Thailand Research Fund, under the TRF Basic Research Grant (Project No. BRG4880010). B.M.R. acknowledges support by the Austrian Science Foundation (FWF Project P16221-N08).

\section{References and Notes}

(1) Frank, H. Chemical Physics of Ionic Solutions; John Wiley \& Sons: New York, 1956.

(2) Williams, R. J. P. Bio-inorganic Chemistry; American Chemical Society: Washington, DC, 1971.

(3) Ohtaki, H.; Radnai, T. Chem. Rev. 1993, 93, 1157.

(4) Bopp, P. In The Physics and Chemistry of Aqueous Ionic Solutions; Reidel Publishing Company: 1987; p 217. 105 .

(5) Rode, B. M.; Schwenk, C. F.; Tongraar, A. J. Mol. Liq. 2004, 110,

(6) Ferguson, E. E.; Fehsenfeld, F. C.; Albritton, D. L. Gas-Phase Ion Chemistry; Academic: New York, 1979.

(7) Waterland, M. R.; Kelley, A. M. J. Chem. Phys. 2000, 113, 6760.

(8) Waterland, M. R.; Stockwell, D.; Kelley, A. M. J. Chem. Phys. 2001, 114, 6249 .

(9) Wahab A.; Mahiuddin, S.; Hefter, G.; Kunz, W.; Minofar, B.; Jungwirth, P. J. Phys. Chem. B 2005, 109, 24108.

(10) Nakahara, M.; Emi, K. J. Chem. Phys. 1993, 99, 5418.

(11) Ikushima, Y.; Saito, N.; Arai, M. J. Phys. Chem. B 1998, 102, 3029.

(12) Laaksonen, A.; Kovacs, H. Can. J. Chem. 1994, 72, 2278.

(13) Kataoka, Y. Bull. Chem. Soc. Jpn. 1993, 66, 2478.

(14) Guilbaud, P.; Wipff, G. J. Phys. Chem. 1993, 97, 5685.

(15) Kato, T.; Hayashi, S.; Oobatake, M.; Katsunosuke, K. J. Chem. Phys. 1993, 99, 3966. 
(16) Ebner, C.; Sansone, R.; Hengrasmee, S.; Probst, M. Int. J. Quantum Chem. 1999, 75, 805.

(17) Dang, L. X.; Chang, T.-M.; Roeselova, M.; Garrett, B. C.; Tobias, D. J. Chem. Phys. 2006, 124, 66101.

(18) Kerdcharoen, T.; Liedl, K. R.; Rode, B. M. Chem. Phys. 1996, $211,313$.

(19) Tongraar, A.; Liedl, K. R.; Rode, B. M. J. Phys. Chem. A 1998, 102,10340 .

(20) Tongraar, A.; Rode, B. M. Phys. Chem. Chem. Phys. 2003, 5, 357.

(21) Tongraar, A.; Rode, B. M. Chem. Phys. Lett. 2005, 403, 314.

(22) Tongraar, A.; Rode, B. M. Chem. Phys. Lett. 2005, 409, 304.

(23) Intharathep, P.; Tongraar, A.; Sagarik, K. J. Comput. Chem. 2005, $26,1329$.

(24) Rode, B. M.; Schwenk, C. F.; Hofer, T. S.; Randolf, B. R. Coor. Chem. Rev. 2005, 249, 2993.

(25) Rode, B. M.; Hofer, T. S. Pure Appl. Chem. 2006, 78, 525.

(26) Rode, B. M.; Hofer, T. S.; Randolf, B. R.; Schwenk, C. F.; Xenides, D.; Vchirawongkwin, V. Theor. Chem. Acc. 2005, 249, 2993.

(27) Dunning, T. H., Jr.; Hay, P. J. In Modern Theoretical Chemistry, III; Plenum: New York, 1976.

(28) Brooks, B. R.; Bruccoleri, R. E.; Olafson, B. D.; States, D. J.; Swaminathan, S.; Karplus, M. J. Comput. Chem. 1983, 4, 187.

(29) Stillinger, F. H.; Rahman, A. J. Chem. Phys. 1976, 68, 666.

(30) Bopp, P.; Jancsó, G.; Heinzinger, K. Chem. Phys. Lett. 1983, 98, 129.

(31) Frisch, M. J.; Trucks, G. W.; Schlegel, H. B.; Scuseria, G. E.; Robb, M. A.; Cheeseman, J. R.; Zakrewski, V. G.; Montgomery, J. A.; Stratmann, R. E.; Burant, J. C.; Dapprich, S.; Millam, J. M.; Daniels, A. D.; Kudin, K. N.; Strain, M. C.; Farkas, O.; Tomasi, J.; Barone, V.; Cossi, M.; Cammi, R.; Mennucci, B.; Pomelli, C.; Adamo, C.; Clifford, S.; Ochterski, J.; Peterson, G. A.; Ayala, P. Y.; Cui, Q.; Morokuma, K.; Malick, D. K.; Rabuck, A. D.; Raghavachari, K.; Foresman, J. B.; Cioslowski, J.; Ortiz, J.
V.; Stefanov, B. B.; Liu, G.; Liashenko, A.; Piskorz, P.; Komaromi, I.; Gomperts, R.; Martin, R. L.; Fox, D. J.; Keith, T.; Al-Laham, M. A.; Peng, C. Y.; Nanayakkara, A.; Gonzalez, C.; Challacombe, M.; Gill, P. M. W.; Johnson, B. G.; Chen, W.; Wong, M. W.; Andres, J. L.; Head-Gordon, M. Replogle, E. S.; Pople, J. A. GAUSSIAN 98; Gaussian, Inc.: Pittsburgh, PA, 1998

(32) Dunning, T. H. J. Chem. Phys. 1989, 90, 1007.

(33) Kendall, R. A.; Dunning, T. H.; Harrison, R. J. J. Chem. Phys. 1992, 96, 6769 .

(34) Woon, D. E.; Dunning, T. H. J. Chem. Phys. 1993, 98, 1358.

(35) Adams, D. J.; Adams, E. H.; Hills, G. J. Mol. Phys. 1979, 38, 387.

(36) Tongraar, A.; Rode, B. M. Chem. Phys. Lett. 2004, 385, 378.

(37) Bopp, P. Chem. Phys. 1986, 106, 205.

(38) Scott, A. P.; Radom, L. J. Phys. Chem. 1996, 100, 16502.

(39) Ebner, C.; Sansone, R.; Probst, M. Int. J. Quantum Chem. 1998 70,877

(40) Irish, D.; Davis, A. Can. J. Chem. 1968, 46, 943.

(41) Irish, D.; Chang, G.; Nelson, D. Inorg. Chem. 1970, 9, 2. 61

(42) Xenides, D.; Randolf, B. R.; Rode, B. M. J. Mol. Liq. 2006, 123,

(43) Xenides, D.; Randolf, B. R.; Rode, B. M. J. Chem. Phys. 2005, $122,174506$.

(44) Murphy, W. F.; Berstein, H. J. J. Phys. Chem. 1972, 76, 1147.

(45) Lock, A. J.; Bakker, H. J. J. Chem. Phys. 2002, 117, 1708.

(46) Deák, J. C.; Rhea, S. T.; Iwaki, L. K.; Dlott, D. D. J. Phys. Chem. A 2000, 104, 4866 .

(47) McQuarrie, D. A. Statistical Mechanics; Harper Row: New York, 1976 .

(48) Woolf, L. A. J. Chem. Soc., Faraday Trans. 1975, 71, 784.

(49) Hofer, T. S.; Tran, H. T.; Schwenk, C. F.; Rode, B. M. J. Comput. Chem. 2004, 25, 211 